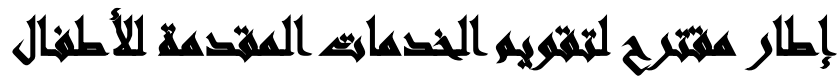

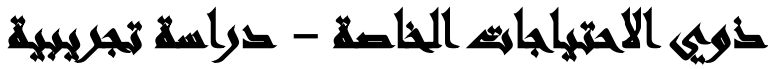

\section{[1 $\leqslant]$}

السيد عطا الشيخ (')- محمد صلاح الدين مصطفى(')- نادر ألبير فانوس(†)

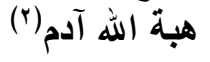

( ) كلية الدراسات العليا للطفولة، جامعة عين شمس r) كلية التجارة، جامعة عين شمس آمس

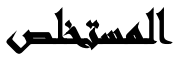

يهدف البحث إلى وضع إطار مقترح لتقويم الخدمات المقدمة للأطفال ذوبي الاحتياجات

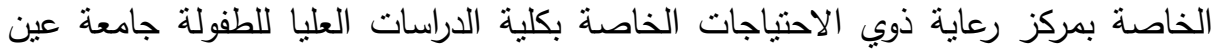

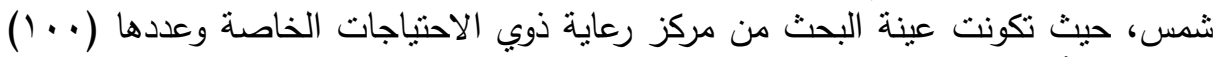

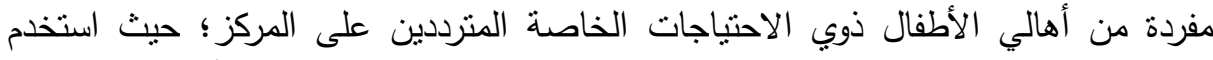

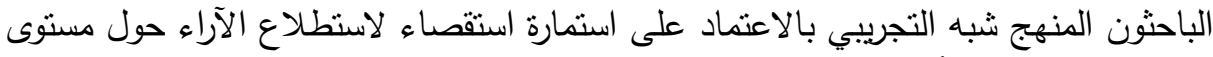

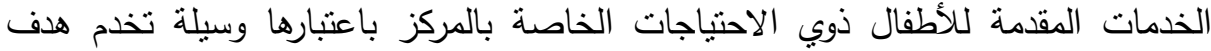

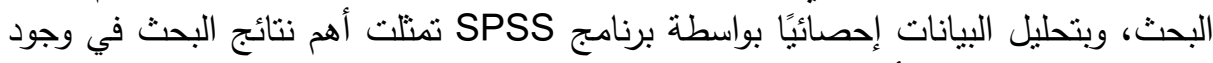

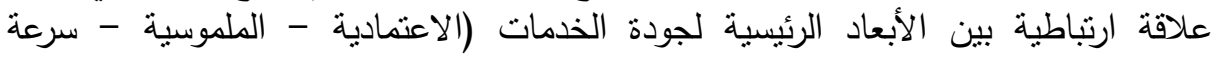
الاستجابة- التوكيد- التعاطف) وبين مستوى جودة الخدمة المقدمة بمركز ذوبة ذوي الاحتياجات

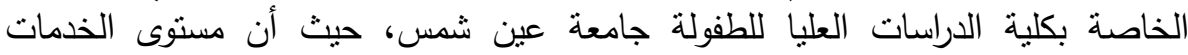

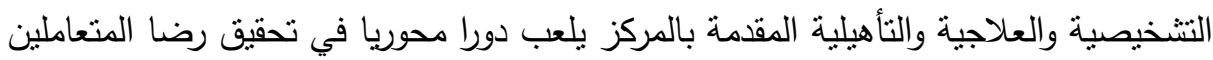

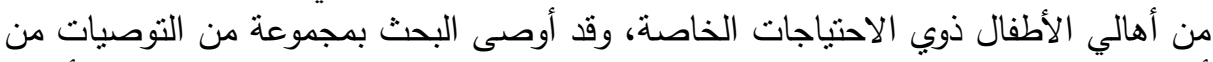

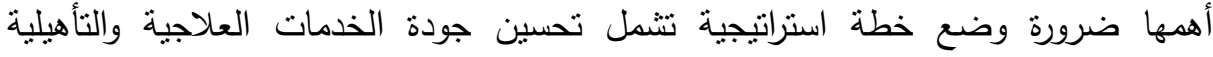

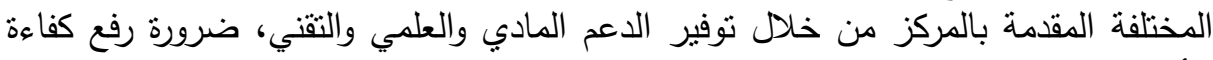

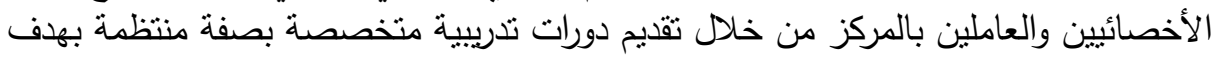

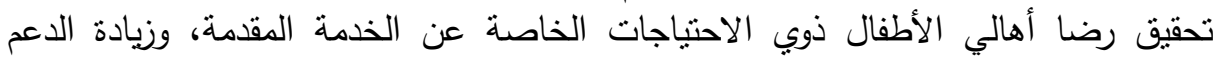

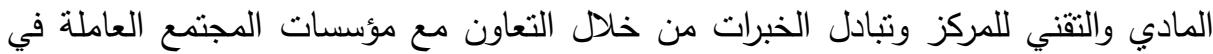

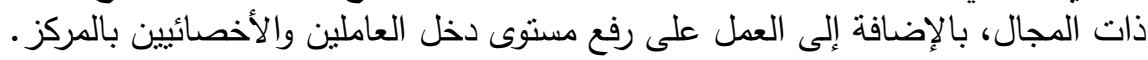




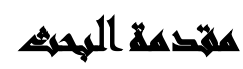

تتبهت العديد من دول العالم في العقود الأخيرة إلى ضرورة الاهتمام بالأفراد ذوي

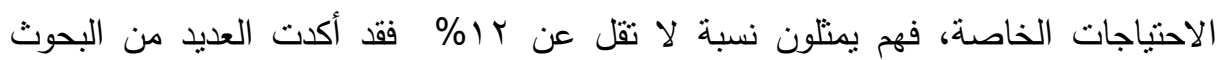

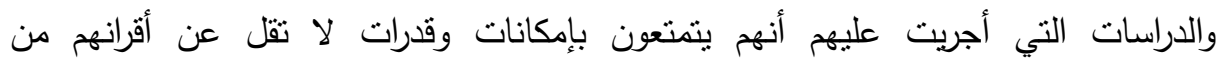

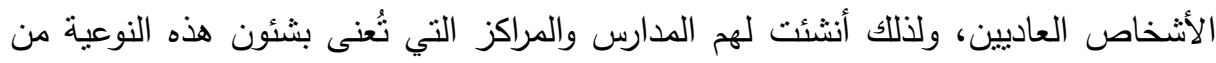

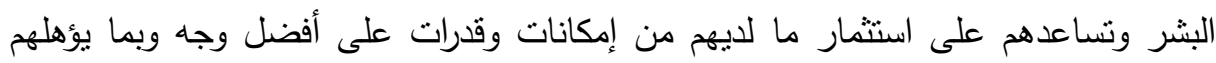
لممارسة حياتهم بصورة طبيعية كغيرهم من العاديين. فالتطور الملحوظ في العقود الأخيرة في مجال رعاية ذوي الاحتياجيات العادئ الخاصة في

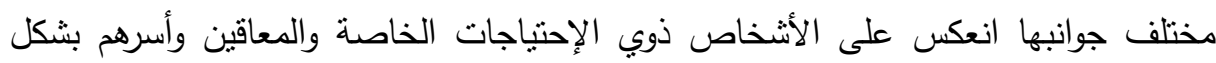

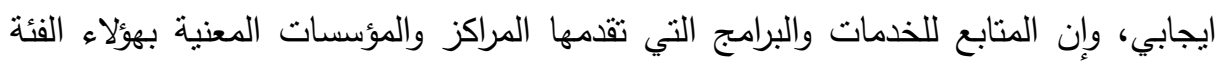

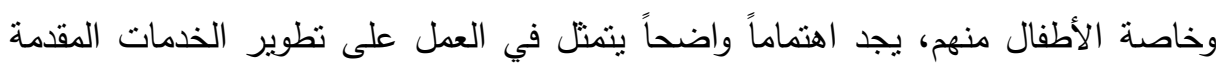

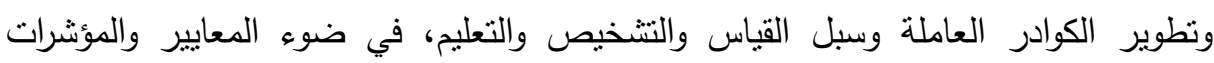

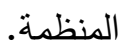

كما أن رعاية ذوي الاحتباجات الخاصة حق أصيل مستمر كفلته الثرائع السماوية

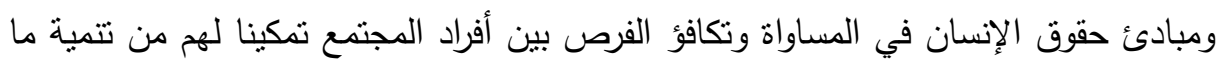

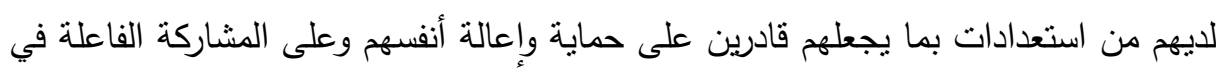

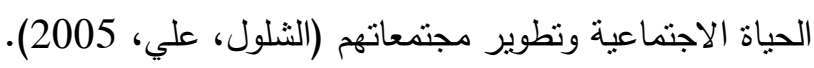

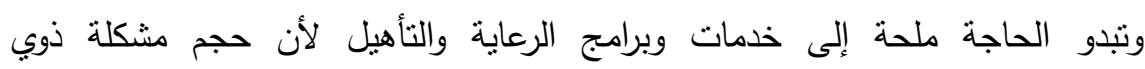

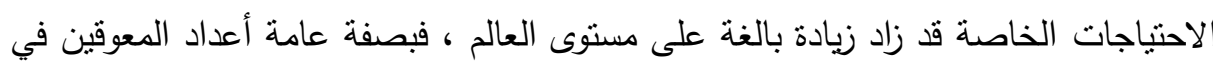

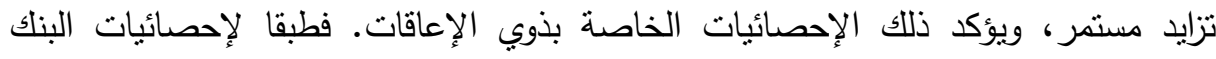

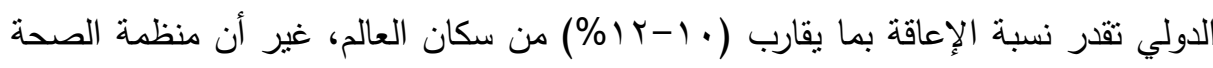

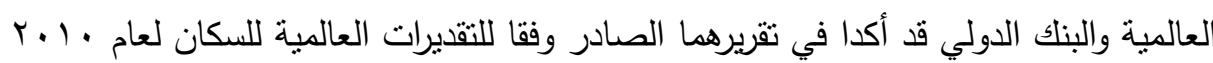

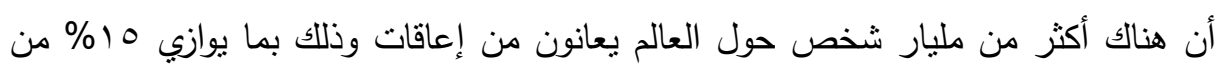

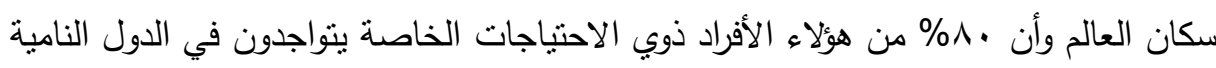

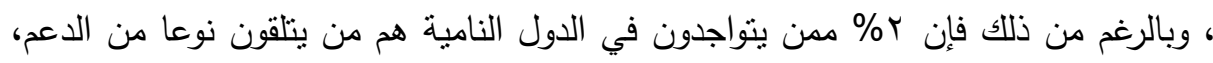


وربما يفسر ذلك أن VI V من فقراء العالم هم من يتلقون نوعا من الدعم أي بعبارة أخرى فإن

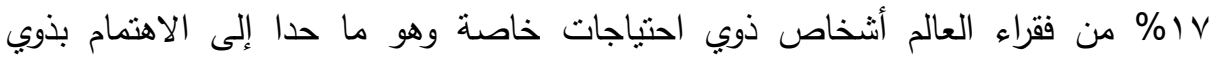

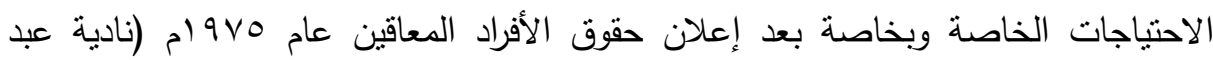

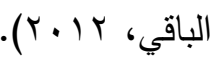
وعليه فإن عملية إيجاد معايير خاصة بالخدمات المقدمة للأطفال ذوي الإحتياجات الخاصة قد شكلت أهم الأولويات لاى المختصين من التربويين والأخصائيين في شئون ذوي الإدي الاحتباجات الخاصة والمعاقين، حيث تهدف هذه الاجراءات إلى تأمين حصول كافة الأطفال

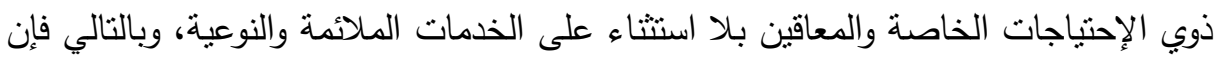
متطلبات تحقيق ذللك تقتضي أن تتضافر جهود جميع المعنيين في المجالات المختلفة الطبية والتزبوية والاجتماعية للعمل معاً وفق خطط عمل إجرائية ومهنية تضمن تحقق تلك الأهداف. والبحث المقترحة "إطار مقترح لتقويم الخدمات المقدمة للأطفال ذوبي الاحتباجات

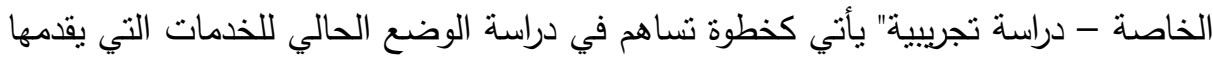

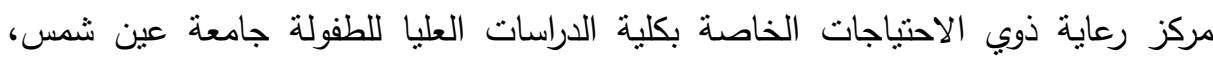
وتقديم مقترح لتحسين جودة هذه الخدمات وتطويرها واستدامتها.

\section{and}

تتمثل مشكلة البحث فيما يلي: يسعى مركز رعاية ذوي الاحتياجات الخاصة بكلية الدراسات

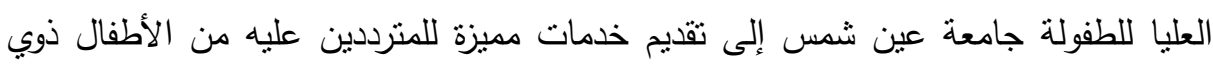

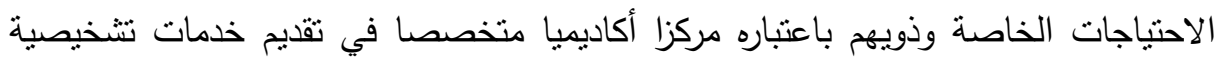

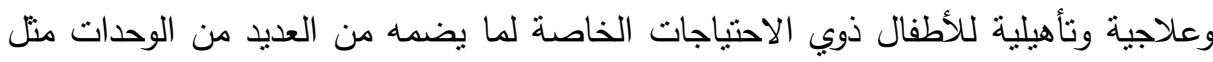

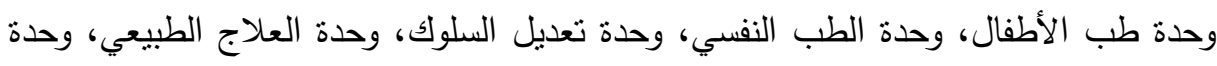

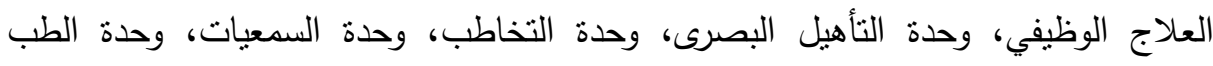
التكميلي..إلخ. 
وقد أعد الجهاز المركزي للتعبئة العامـة والإحصـاء المصري دراسة عن حجم الاعاقة في

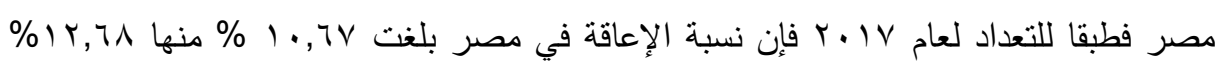

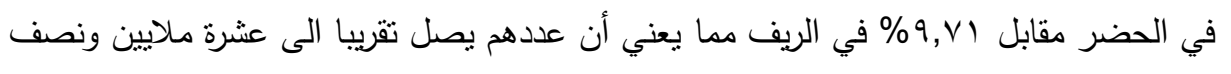
شخص، ولكن المشكلة الأكبر تتمثل في ضآلة عدد الذين بحصلون على الخدمات والرعاية منهم.

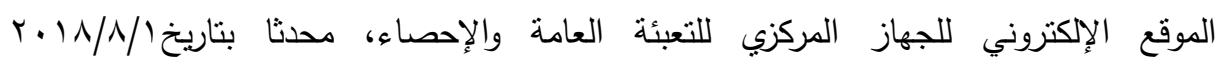
(https://www.capmas.gov.eg/Pages/IndicatorsPage.aspx?page_id) إذ تؤكد مديرية النأهيل بوزارة التضامن الاجنماعي أن الذين يحصلون على خدمات

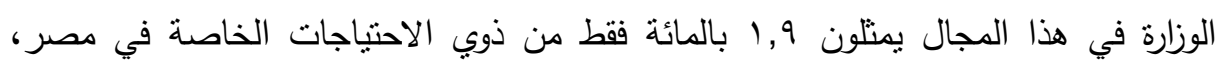

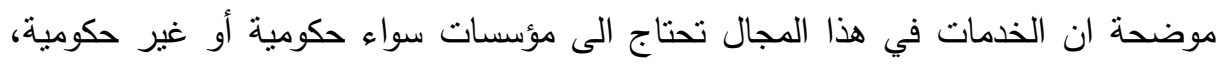

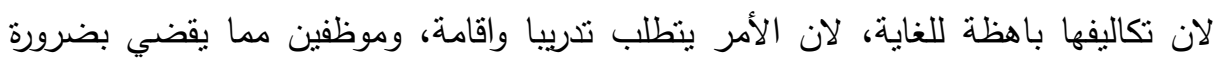

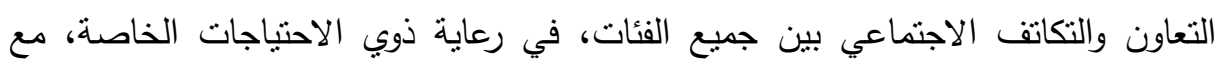

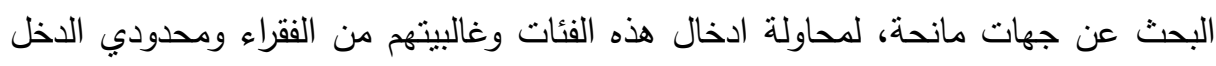
في عملية التتمية بدلا من أن يكونوا عالة عليها. (الموقع الإلكتروني للهيئة العامة للاستعلامات (http://www.sis.gov.eg/News/Search?lang=ar/12487r)

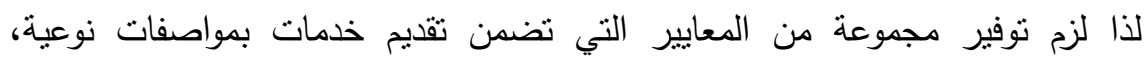

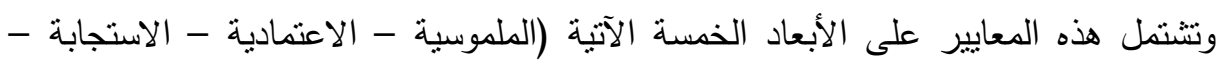

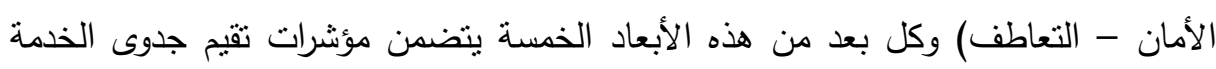
المقدمة. (Parasuraman, Zeithaml, Berry, 1988)

وعلى الرغم من الجهود الكبيرة المبذولة في رعاية الأطفال ذوي الاحتياجات الخاصة؛ إلا

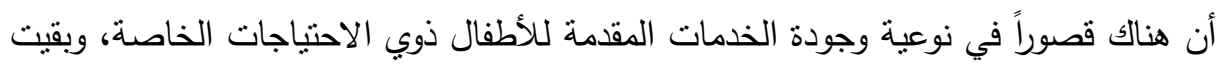

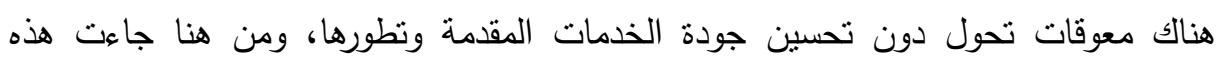

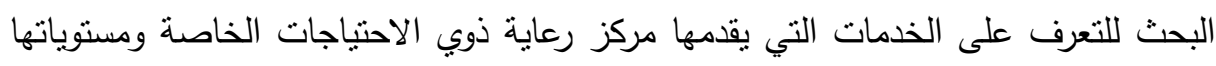

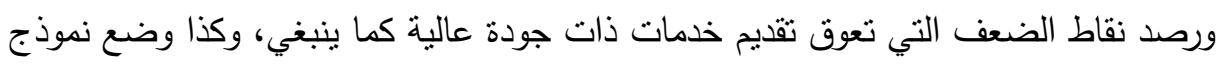
مقترح لتقويمها وتحسينها واستدامتها في ضوء معايير جودة الخدمات. 


\section{أمساهن الهمبه}

يهذف البحث إلى تحقيق الأهداف التالية: يرتكز هذا البحث إلى العديد من الأهداف العامة والخاصة أما الهدف العام فهو تقويم الخدمات المقدة للأطفال ذوي الاحتياجات الخاصة، وتتمثل الأهداف الفرعية فيما يأتي:

• رصد الخدمات المقدمة للأطفال ذوبي الاحتياجات الخاصة بمركز رعاية ذوبي الاحتباجات

$$
\text { الخاصة بكلية الدراسات العليا للطفولة جامعة عين شمس. }
$$

• دراسة جدوى الخدمات المقدة بمركز رعاية الأطفال ذوي الاحتباجات الخاصة من خلا لعل التعرف على أهم الاستراتيجيات المستخدمة من قبل إدارة المركز للوقوف على نقاط القوة ونقاط الضعف.

• قياس رضا العاملين والأخصائيين وأهالي الاطفال ذوي الاحتياجات الخاصة عن الخدمات

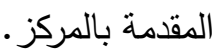

• وضع اطار مقترح لتقويم الخدمات المقدمة والتغلب على نقاط الضعف وتدعيم نقاط القوة بالمركز بهذف تحسين مستوى الخدمات وتطويرها واستدامتها.

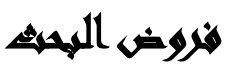

الفرض الرئيسي: تتحقق أبعاد قياس جودة الخدمة المقدمة (الاعتمادية - الملموسية -

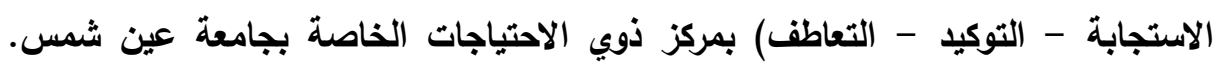
ويتفرع من هذا الفرض الرئيسي الفروض الفرعية الآتية:

1-الفرض الفرعي الأول: "تتحقق عناصر الملموسية كأحد أبعاد جودة الخدمة المقدمة بمانية بمركز

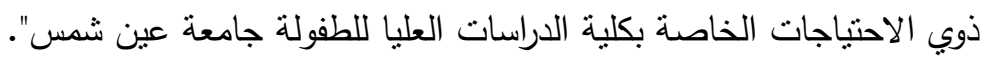

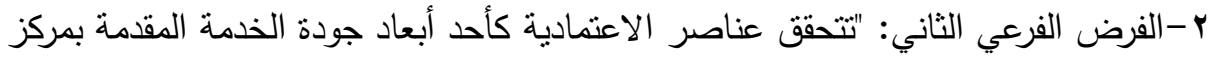

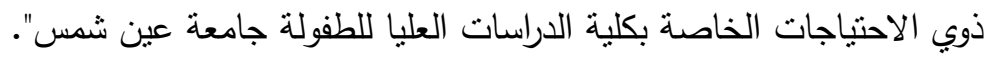

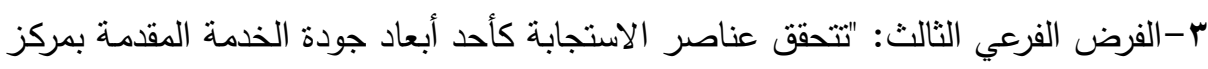

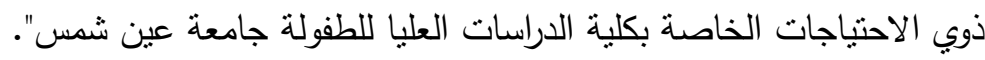


ـ -الفرض الفرعي الرابع: "تتحقق عناصر الثقة كأحد أبعاد جودة الخدمة المقدمة بمركز ذوبي

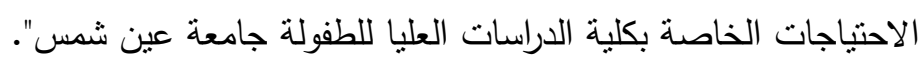

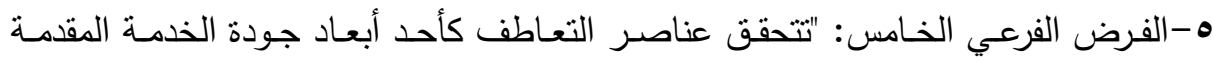

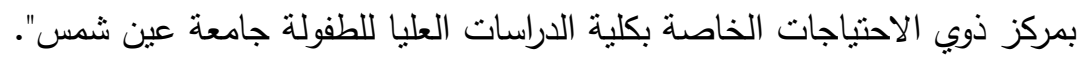

\section{الصواسايت الماريخة}

أولاً: الاراسات العربية:

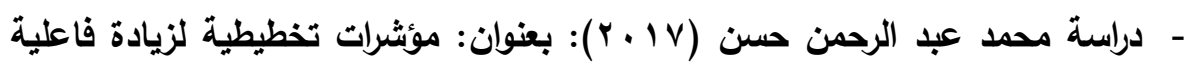
فريق العمل في تقديم رعاية المتكاملة للمعاقين بصرياً أهداف البحث: (التعرف على بعنى أنواع الرعاية المتكاملة للمعاقين بصريا من خلال فريق العمل داخل المدرسة، التعرف على التى مدى التعاون والتكامل والتتسيق بين أعضاء فريق العمل مع المعاقين بصري أو إمكانية

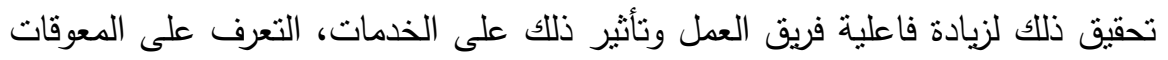

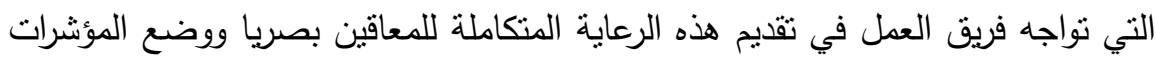

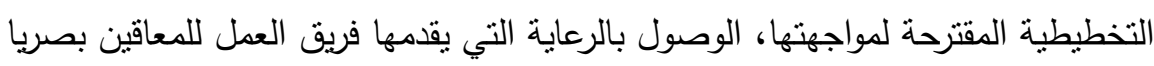
إلى المستوى الذي يحقق التكامل في توجيه خدمات الرعاية الاجتماعية إلى هذه الفئة).

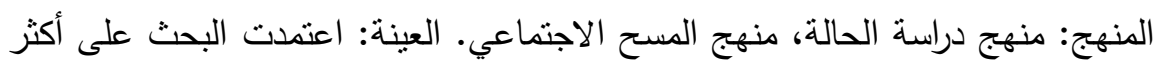

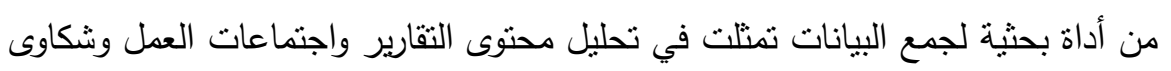
الطلاب الاقتراحات، الملاحظة البسيطة.

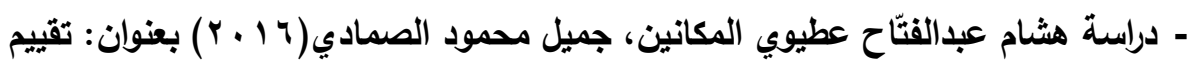

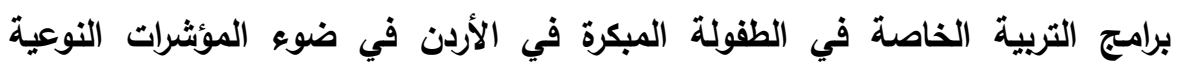

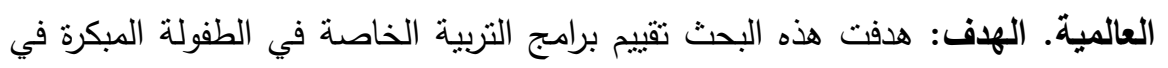

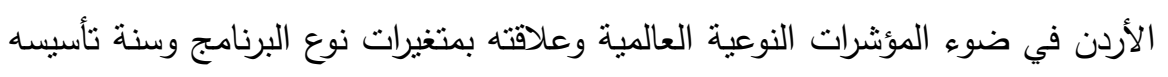

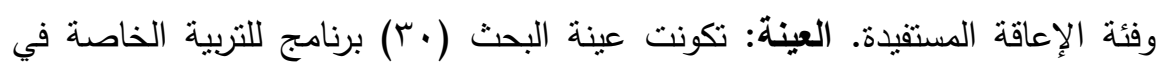
الطفولة المبكرة تتبع لقطاعات حكومية وخاصة وتطوعية. النتائج: أنشارت نتائج البحث

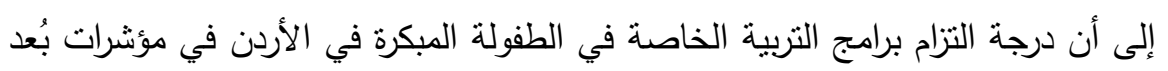


التقييم كان بدرجة مرتفعة بمتوسط حسابي بلغ (0.85) في حين أن درجة التزام برامج

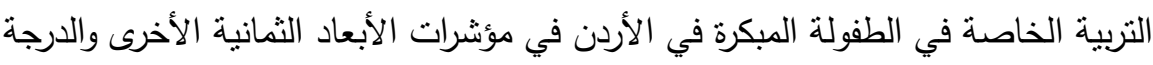
الكلية كانت متوسطة وهي على النحو الآتي: بلغ المتوسط الحسابي لبُعدي الخدمات

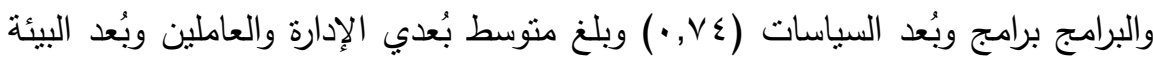

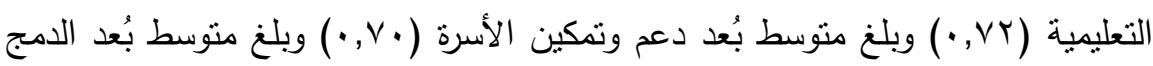

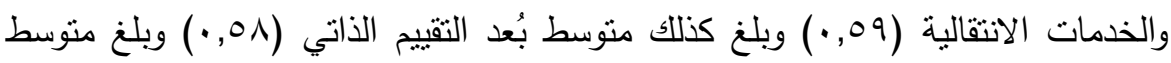

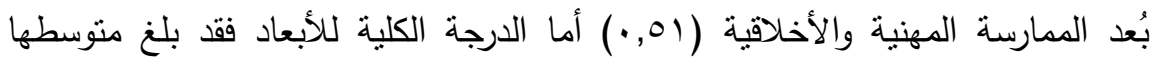

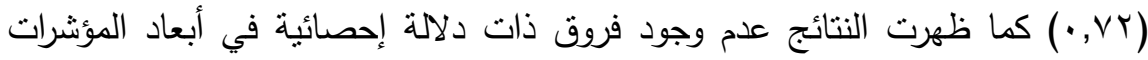
النوعية العالمية تعزى لمتغيرات نوع البرنامج وسنة تأسيسه وفئة الإعاقة المستفيدة.

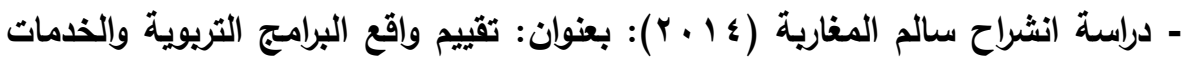

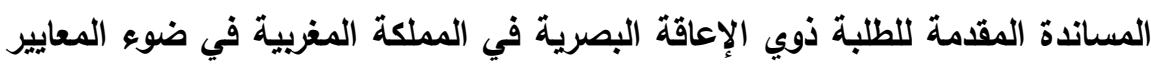

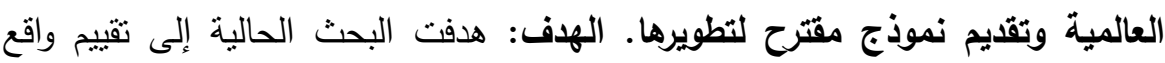
البرامج التربوية والخدمات المساندة المقدة للطلبة ذوي الإعاقة البصرية في المغرب في

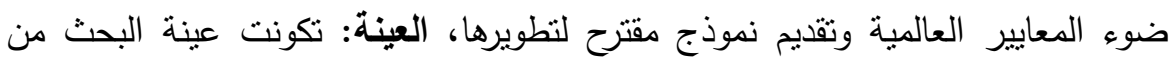

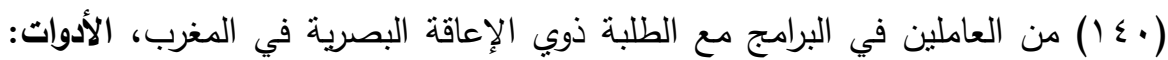
استبانة تقييم واقع البرامج التزبوية والخدمات المساندة المقدمة للطلبة ذوي الإعاقة البصرية في المغرب في ضوء المعايير العالمية بعد التوصل إلى المكونات والأبعاد الاساسية لهذه

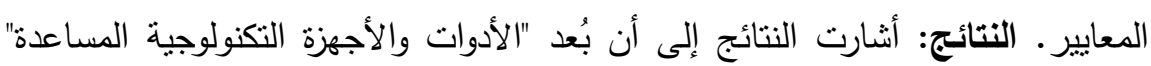

$$
\text { انطبق بدرجة مرتفعة بمنوسط ؟. }
$$

- دراسة محمد علي أحمد السوالمة (2013): بعنوان: تقييم فاعلية الخدمات المقدمة للأفراد ذوي الإعاقات المتعددة في مؤسسات التربية الخاصة في الأردن من وجهة نظر لـانه

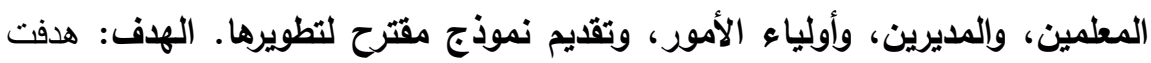

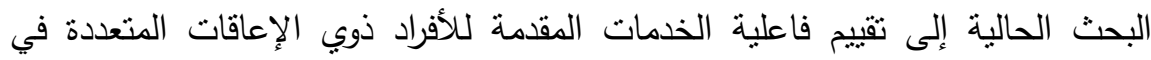
مؤسسات التربية الخاصة في الأردن من وجهة نظر المعلمي، والمديرين، وأولياء الأمور، الإهـ

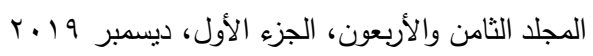


ومعرفة ما اذا كان هناك فروق ذات دلالة احصائية في مستوي فاعلية الخدمات المقدمة

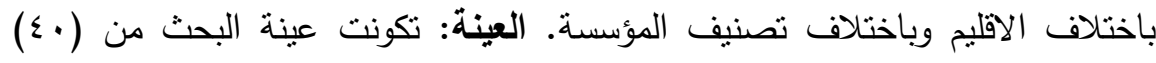
مؤسسة من مؤسسات التربية الخاصة التي تقدم خدماتها للأفراد ذوبي الإعاقات المتعددة

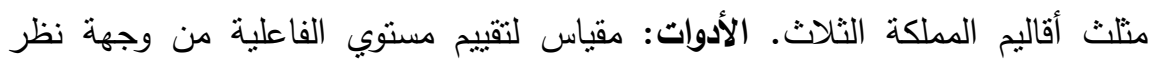

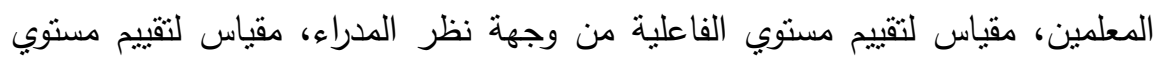
الفاعلية من وجهة نظر أولياء الأمور، ونم التوصل إلى دلالات الصدق والثبات للأدوات بررت استخدامها. النتائج: أشنارت النتائج إلى وجود اختلاف في في مستوي فاعلية الخدمات

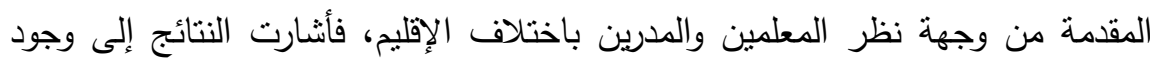

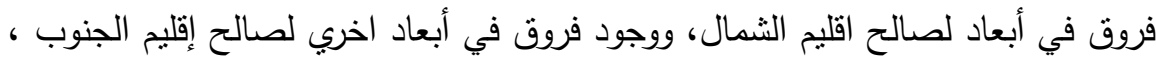

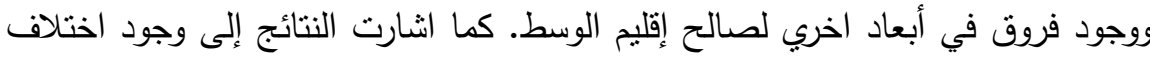
في مستوي فاعلية الخدمات المقدمة من وجهة نظر المعلمين والمدرين باختلاف تصنيف

- دراسة عاكف عبدالله الخطيب (11 + r): بعنوان: نموذج مقترح لتطوير البرامج والخدمات المقدمة للأطفال ذوي الإعاقة العقلية واضطراب التوحد في مؤسسات ومراكز التربية

\section{الخاصة في الأردن في ضوء المعايير العالمية}

الهـف: هدفت الدراسة الي تطوير نموذج مقترح لتطوير البرامج والخدمات المقدمة للأطفال

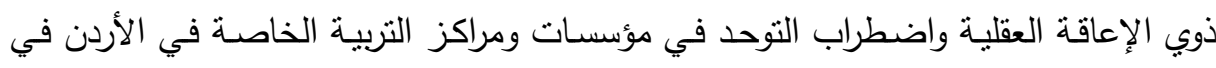

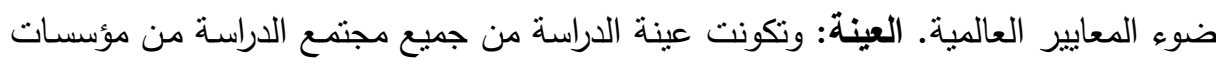

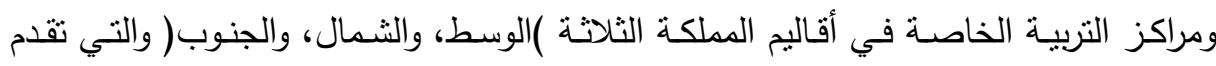

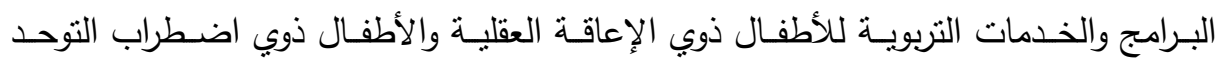

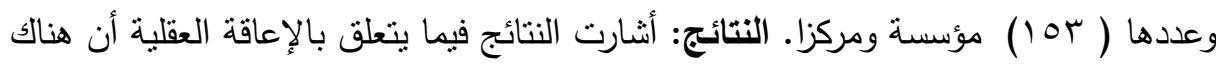

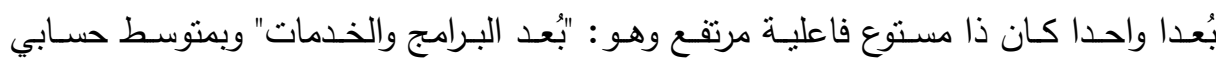

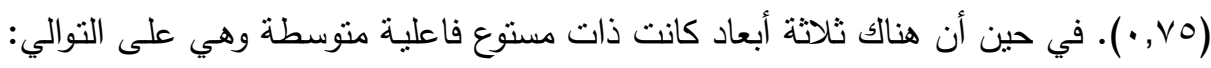

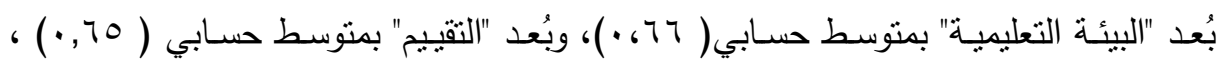

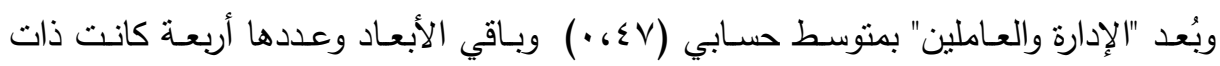


مستوع فاعلية متدنية وهي: بُعد وبُعد "الروئية والفكر والرسالة" بمتوسط ( بس، ·)، و "مثـاركة

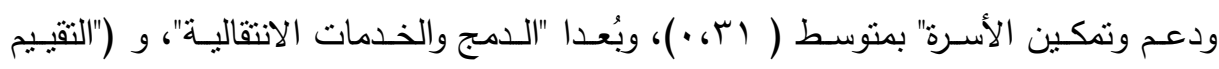

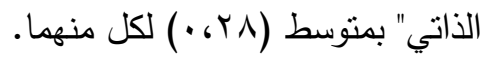

$$
\begin{aligned}
& \text { ثانياً: الدراسات الأجنبية: }
\end{aligned}
$$

- دراسة Griffin . Shirley 2017 -

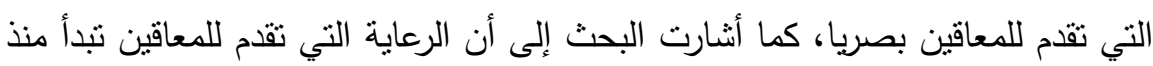

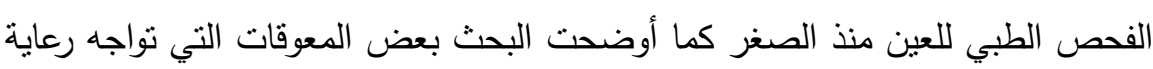

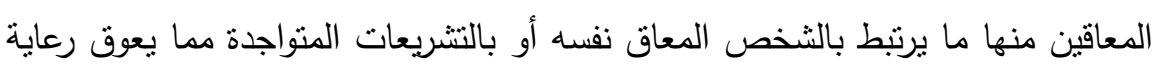
هؤلاء الفئة من المعاقين. - دراسة Pardey Kennetn 2014 سواء أكانت صحية أو اجتماعية أو تعليمية أو ترويحية والتي تقدم للمعاقين بصرياً ودور

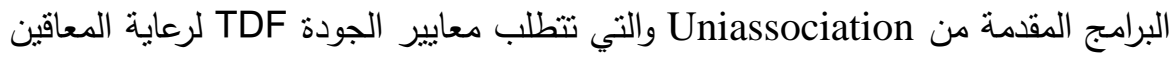

- دراسة Bradley N. Hedrick, Norma J. Stumbo, David 2012 البحث إلى نوثيق الدعم المساند للأفراد ذوي الإعاقات الثديدة في التعليم، ونم نطبيق البحث من خلال استبيان طبق على حوالي جب فردا من ذوي الإعاقات الجسمية الثديدة

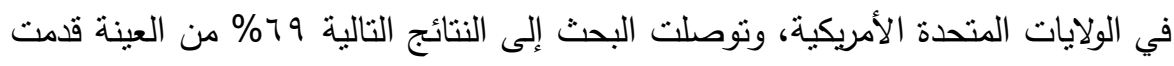

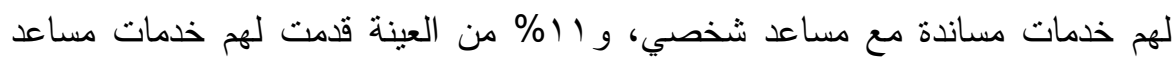
شخصي فقط، أوضحت البحث أن الأفراد الذين لم يقدم لهم خدمات الدعم المساند تركت في نفوسهم آثارا سلبية على العكس نركت تلاك الخدمات ارتياحا في نفوس من قدمت لهم

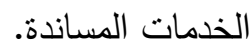
- دراسة ( Cornetj . Judy 2011 - اهتمت الدراسة بالخدمات المتتوعة التي تقدم لذوي الاعاقات السمعية من قبل اتحاد الطب الأمريكي وكذللك جمع التبرعات والأموال لتدعيم تلك الخدمات وتوفيرها بالكم والكيف الملائمين لهذه الفئة من ذوي الاحتباجات الخاصة،

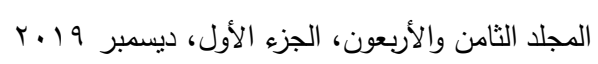


وكانت Lend A Neville رائدة في هذا المجال في رعاية المعاقين سمعيا والعمل على تجميع تلك التبرعات التي تساعد على رعايته وحل المشكلات التي يعانوا منها.

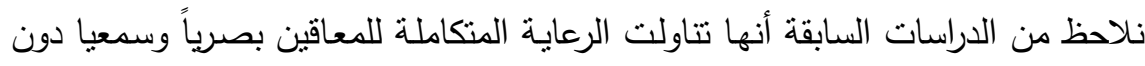
التركيز على دور الفريق في تقديم هذه الرعاية حيث استفادت الدراسـة الحالية في تحديد اوجها

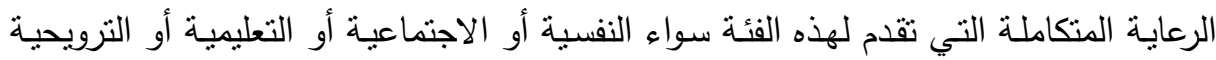
والتي تساعد على حل مشكلاتهم وزيادة التوافق بينهم وبين بيئاتهم.

\section{الإطار اللنظليه}

\section{مصطلحات البحث: Terms of study}

إطار مقترح: تصور إدراكي للمجالات أو المحاور التي يتكون منها النظام ويتضمن جميع العناصر المكونة للنظام وهو نرجمة لنظريات ثبتت مصداقيتها أكاديميا، وخلاصة فكر إنساني أكاديمي متخصص وجه علمي بستتد إلى التجربة والمقارنة ويعتمد على معايير إدارية وفنية

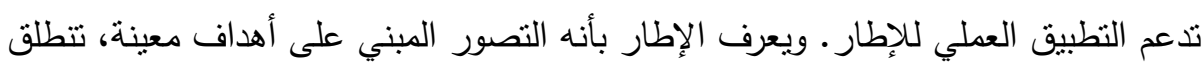

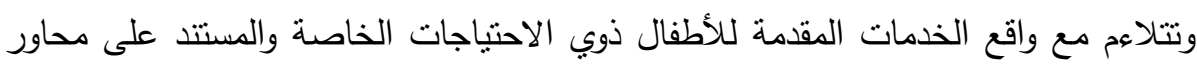

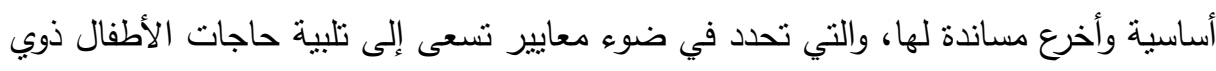
الاحتياجات الخاصة ومنطلبات ذويهر. تقويم الخدمات: يعرف كل من جارجيلو وكيلجو (Gargiulo \& Kilgo, 2000) عملية

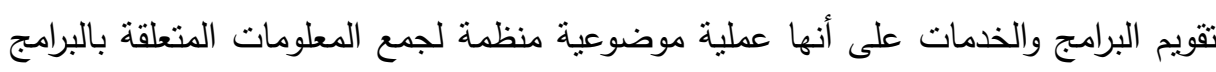
والخدمات وأنشطتها المختلفة للأغراض للتأكد من قدرتها على تحقيق الغايات والأهداف التي لتهني أقيمت من أجلها واقتراح التعديلات التي قد تؤدي إلى تحسين نوعية وفاعلية الخدمات المقدمة،

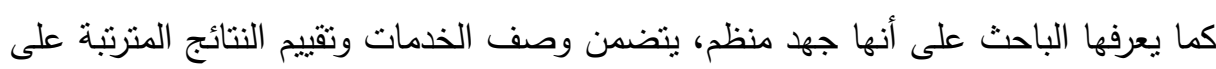
اجراءات بهدف تقديم المعلومات والتغذية المرتدة المفيدة لاتخاذ قرارات مناسبة فيما يتعلق بجدوى الخدمات وتحليل مدى تحقيقها للأهداف المنوقعة منه. 
ذوي الاحتياجات الخاصة ليس هناك إجماع على توحيد معايير هذا المصطلح، وهكذا فقد يعتبر شخص من ذوي الاحتياجات الخاصة حسب مفهوم بعض الدول ولا يعتبر كذلك في

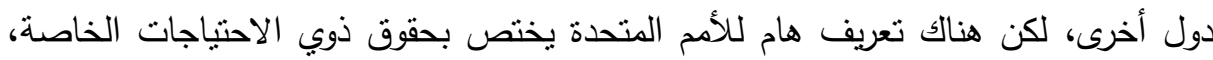

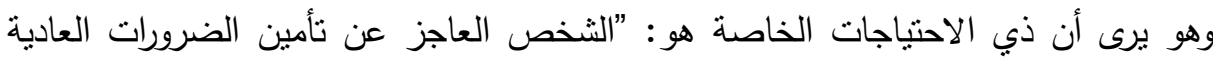

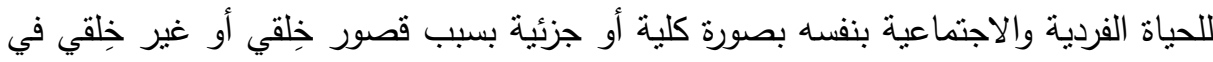

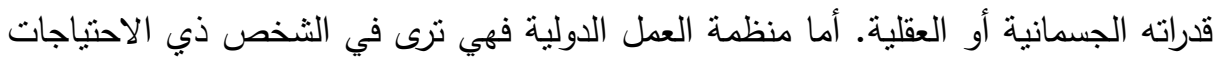

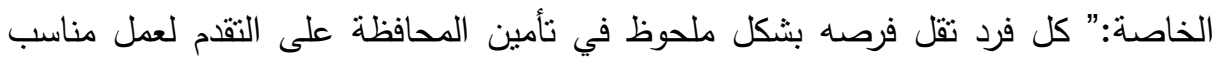

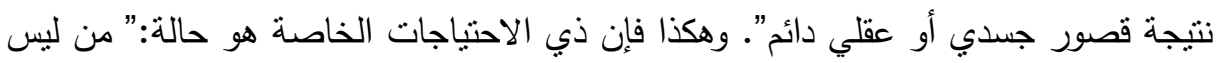

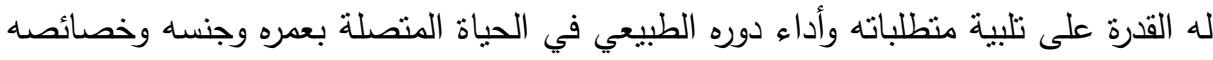

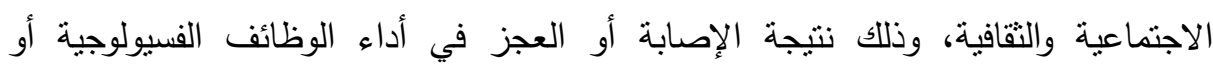
الاجتماعية". فالأفراد ذوو الاحتباجات الخاصة أو ذوو الاحتباجات غير العادية هم الأفراد

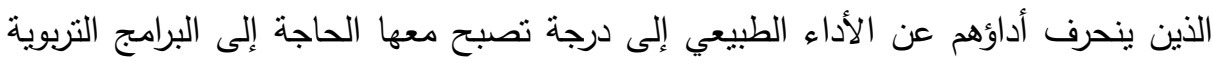

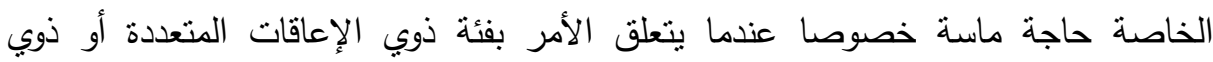

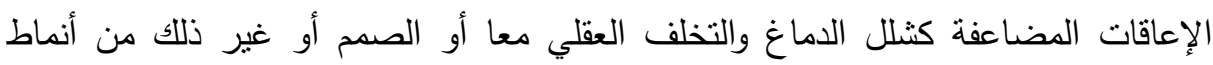
الإصابة بأكثر من إعاقة، وعليه فإننا يمكن أن نجمل تعريف الأطفال ذوي الاحتياجات

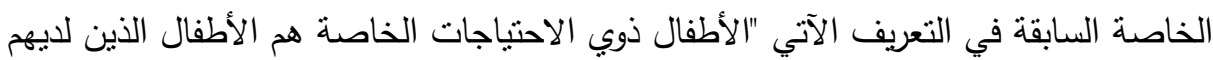

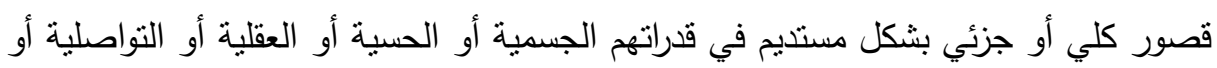
الأكاديمية أو النفسية إلى الحد الذي يستوجب تقدئي خدمات التربية الخاصة من قبل مراكز 


\section{منهمج الهيهA}

من أجل تحقيق أهداف البحث قام الباحثون باستخدام المنهج شبه التجريبي لتكوين الإطار النظري للبحث في جمع البيانات باستخدام مصدرين أساسين للمعلومات:

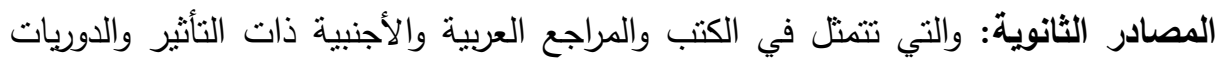

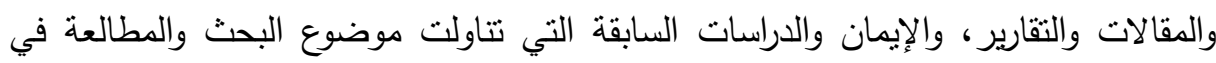

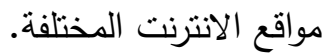
المصادر الأولية: والتي تتمنل في جميع البيانات الأولية من خلال استمارة استقصاء كأداة رئيسية للبحث ثم توزيعها على عينة البحث.

\section{مصورت المجمه}

$$
\begin{aligned}
& \text { تتمثل حدود البحث في الأتي: }
\end{aligned}
$$

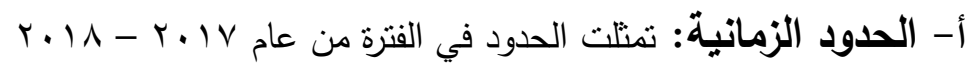

ب- الحدود المكانية: تمثلت الحدود المكانية في مركز رعاية ذوي الاحتباجات الخاصة بكلية الدراسات العليا للطفولة جامعة عين شمس

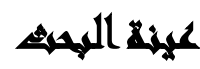

اقتصر البحث على عينة عمديه من أهالي الأطفال ذوي الاحتياجات الخاصة المترددين

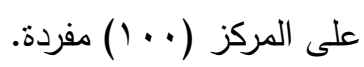

\section{إلجراعائه المهنه}

أداة البحث: نم تصميم استمارة استبيان لاستطلاع آراء أهالي الأطفال ذوي الاحتياجات الخاصة المتعاملين مع المركز حول مستوى جودة الخدمات المقدمة لأطفالهم، تتألف الاستمارة من خمسة أبعاد رئيسية مشتملة على اثتتين وعشرين عبارة، وهذه الأبعاد هي: (البعد الأول:

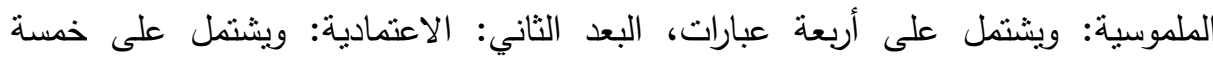


عبارات، البعد الثالث: الاستجابة: ويشتمل على أربعة عبارات، البعد الرابع: ويشتمل على

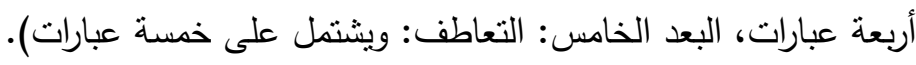

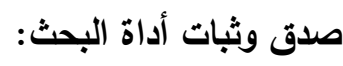
ثبات الاستبيان: للتحقق من ثبات الاستبيان لإمكانية الاعتماد على نتائج الاستيان استخدم الباحث معادلة ألفا كرونباخ (Alpha Cronbach)، ويوضح الجدول التالي معاملات الثبات الناتجة باستخدام هذه المعادلة. جدول (1) - نبات العبارات لأبعاد جودة الخدمة

\begin{tabular}{|c|c|c|}
\hline قيمة آلفا & عدد العبارات & آبعاد جودة الغدمة \\
\hline .,0V9 & 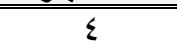 & الملموسية \\
\hline$\cdot, 701$ & 0 & الاعتمادية \\
\hline$\cdot, 0 \wedge \varepsilon$ & $\varepsilon$ & الاستجابةٌ \\
\hline$\cdot, 7 \wedge 9$ & $\varepsilon$ & الثقة \\
\hline$\cdot, 791$ & 0 & التعاطف \\
\hline TVO & TY & إجمالى جودة الخدمة \\
\hline
\end{tabular}

يتضح من الجدول السابق أن قيم معاملات الثبات جميعها قيم جيدة حيث تراوحت قيم

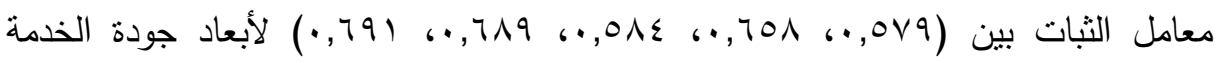
(الملموسية - الاعتمادية - الاستجابة - النقة - التعاطف) على التوالي وهي قيم مرتفعة أكبر

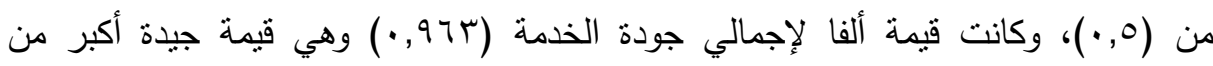

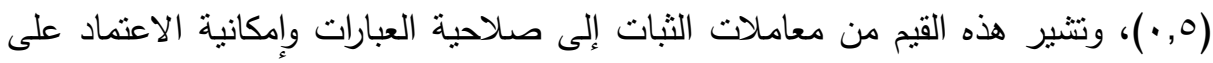

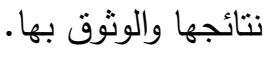


صدق الاتساق الداخلي للاستبيان: نم حساب معاملات ارتباط كل بعد من أبعاد جودة الخدمة

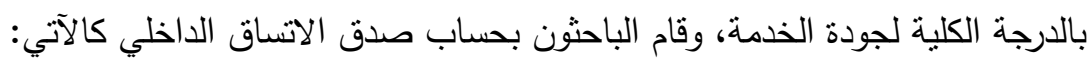
جدول (ץ): صدق الاتساق الداخلي جودة الخدمة

\begin{tabular}{|c|c|c|}
\hline الالالة المعنويـة & معامل ارتباط بيزسون & أبعاد جودة الخدمة \\
\hline$\cdot, \cdot r$ & $\left.\left({ }^{* * *}\right) \cdot, \Gamma\right)$ & الملموسية \\
\hline$\cdot, \cdots 1$ & $\left.\left({ }^{* * *}\right),, \vee \vee\right\urcorner$ & الاعتمادية \\
\hline$\cdot, \cdots 1$ & $\left({ }^{* * *}\right) ., 01 \mathrm{~V}$ & الاستجابة \\
\hline$\cdot, \cdots 1$ & $\left({ }^{* * *}\right) ., 001$ & الثقة \\
\hline 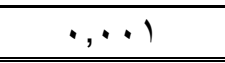 & $\left({ }^{(* *}\right) \cdot, \wedge I r$ & التعاطف \\
\hline
\end{tabular}

من جدول صدق الاتساق الداخلي السابق لأبعاد جودة الخدمة نجد أن معامل الارتباط

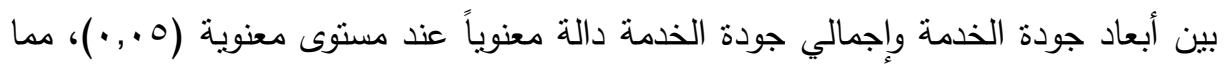

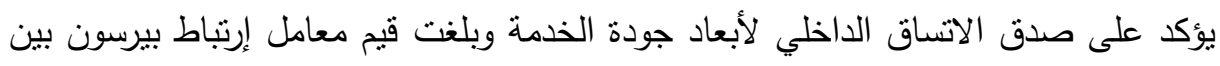

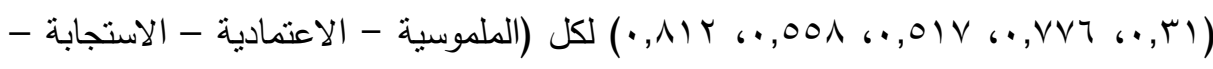
التقة - التعاطف) على التوالي.

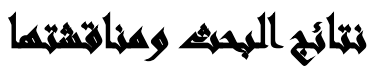

\section{اختبار صحة الفروض:}

الفرض الرئيسي: تتحقق أبعاد جودة الخدمة (الاعتمادية والملموسية والاستجابة والتوكيد والتعاطف) المقدمة بمركز ذوي الاحتياجات الخاصة بجامعة عين شمس. قام الباحثون بتحليل

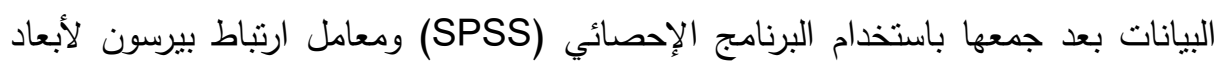

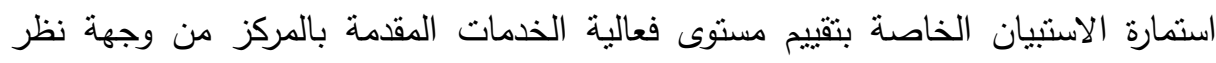
أهالي الأطفال ذوي الاحتياجات الخاصة المترددين على المركز وكانت النتائج: 
جدول (ץ): يوضح العلاقة الارتباطية بين أبعاد جودة الخدمات ومستوى الخدمة المقدمة من

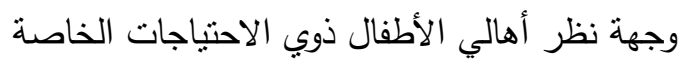

\begin{tabular}{|c|c|c|c|c|}
\hline 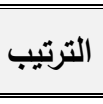 & الوزن النئوي & المعياري الإنحراف & الحستوسط & أبعاد مقياس جودة الخدمات المقدمة \\
\hline الثالث & VI, ro & 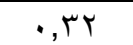 & $r, 1 \varepsilon$ & البعد الأول: الملموسية \\
\hline الثانى & $V 1,7 V$ & $\cdot, T Y$ & $T, 10$ & البعد الثاني: الإعتمادية \\
\hline 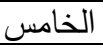 & $77, \wedge T$ & $\cdot, 19$ & $Y, .1$ & البعد الثالث: الاستجابة \\
\hline الأول & $V Y, \cdot \Lambda$ & $\cdot$, ro $_{0}$ & $r, 17$ & البعد الرابع: الثقة \\
\hline الرابع - م الرابع & $v \cdot, \ldots$ & 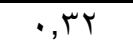 & T,1. & البعد الخامس: التعاطف \\
\hline & $v \cdot, 01$ & $\cdot, 19$ & $T, I Y$ & جودة الخدمة \\
\hline
\end{tabular}

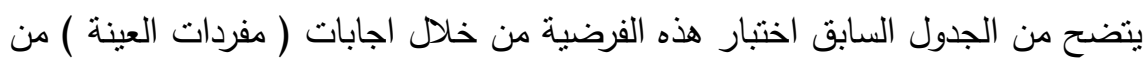

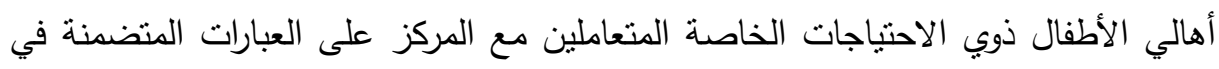

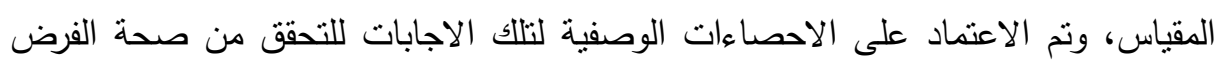
وتبين النالي:

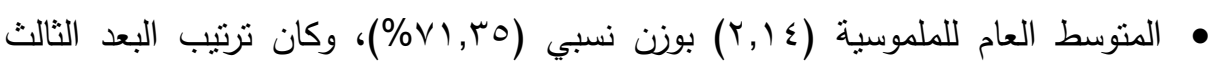
بالنسبة لأبعاد جودة الخدمة.

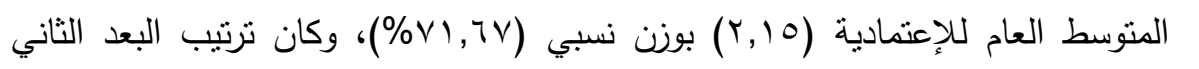
بالنسبة لأبعاد جودة الخدمة.

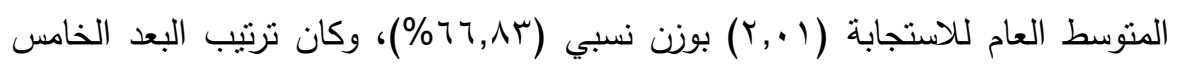
بالنسبة لأبعاد جودة الخدمة.

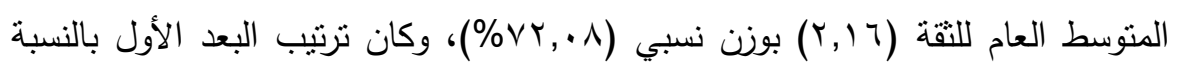
لأبعاد جودة الخدمة.

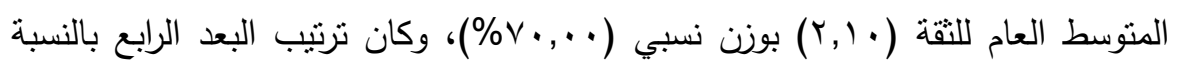
لأبعاد جودة الخدمة.

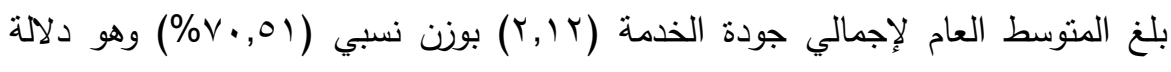
على موافقة العينة على عبارات جودة الخدمة ككل. 
من النتائج السابقة ثبت صحة الفرض الرئيسي "تتحقق أبعاد جودة الخدمة ( الاعتمادية والملموسية والاستجابة والتوكيد والتعاطف ) المقدمة بمركز ذوي الاحتباجات الخاصة بجامعة التئية عين شمس. الفرض الفرعي الأول: "تتحقق عناصر الملموسية كأحد أبعاد جودة الخدمة المقدة بمركز

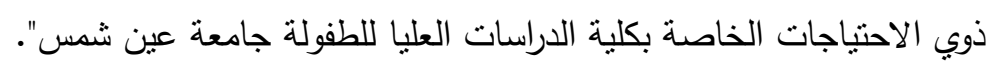

\begin{tabular}{|c|c|c|c|c|}
\hline \multicolumn{5}{|c|}{ جدول (؛ ): نتائج الإحصاء الوصفي لعبارات الملموسية } \\
\hline الترتيب & المزائن النسبي & المعياري & المتوسط & 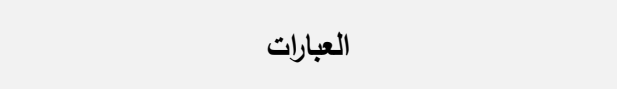 \\
\hline$r$ & 79,1 . & $\cdot, 7 \leqslant$ & $r, \cdot v$ & المستخدمة المركز إلى تحديث الأجهزة والأدوات العلاجية \\
\hline 1 & $\vee ৭, \wedge T$ & $\cdot, \leqslant 9$ & r, $\varepsilon$. & 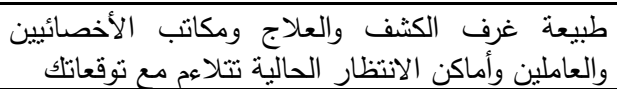 \\
\hline$\varepsilon$ & $7 r, \wedge 9$ & $\cdot, V Y$ & 1,94 & 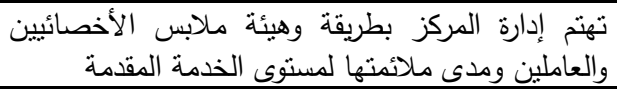 \\
\hline r & $V Y, O V$ & $\cdot, 0$. & $r, 1 \wedge$ & 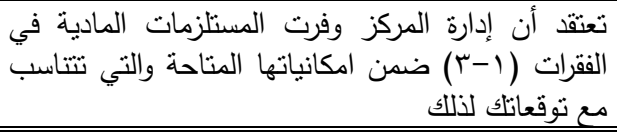 \\
\hline
\end{tabular}

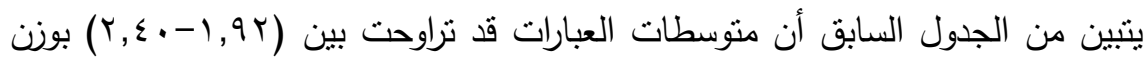

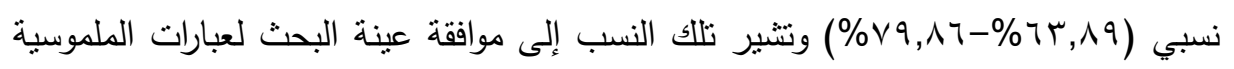

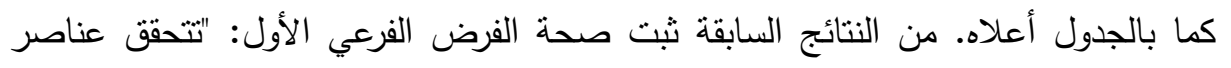
الملموسية كأحد أبعاد جودة الخدمة المقدمة بمركز ذوبي الاحتياجات الخاصة بكلية الدراسات العليا للطفولة جامعة عين شمس". الفرض الفرعي الثاني: "تتحقق عناصر الاعتمادية كأحد أبعاد جودة الخدمة المقدمة بمركز

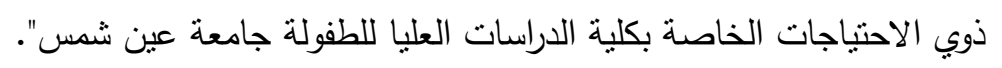


مجلة العلوم البيئية

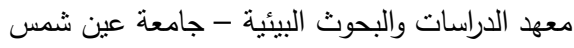

جدول (•): نتائج الإحصاء الوصفي لعبارات الإعتمادية

\begin{tabular}{|c|c|c|c|c|}
\hline الترتيب & 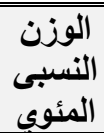 & المعياري & المسابي المتي & العبارات \\
\hline$r$ & r & •, ६. & $r, 11$ & 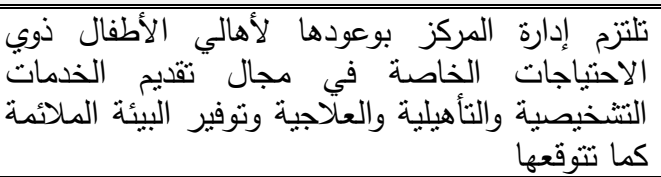 \\
\hline 0 & Vד, & • TV & $r, \ldots$ & 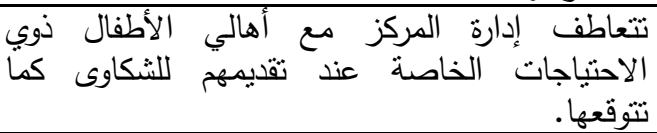 \\
\hline$\varepsilon$ & $79,7 \vee$ &., 00 & $r, \cdot q$ & تالهحد إدارة المركز بتقديم ودقيق الخدمات المختلفة في الوقت \\
\hline$r$ & $V 0,7 \mathrm{~V}$ & $\cdot, \leqslant 9$ & $r, Y V$ & 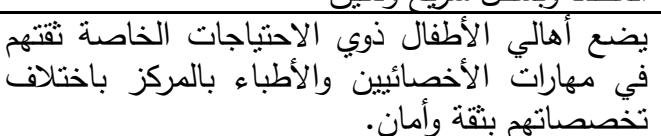 \\
\hline 1 & $\vee \tau, \cdots$ & $\cdot, 01$ & $r, Y \wedge$ & 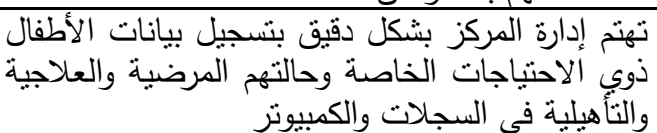 \\
\hline
\end{tabular}

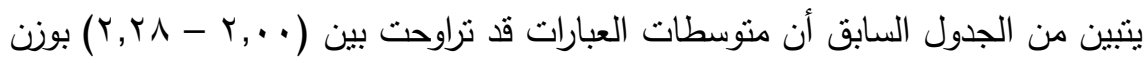

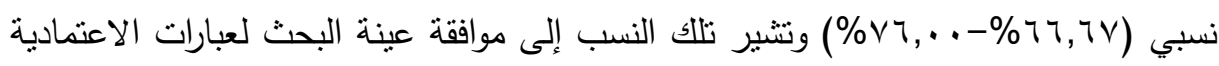

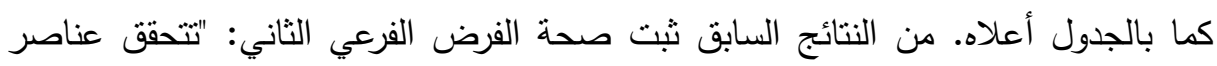
الاعتمادية كأحد أبعاد جودة الخدمة المقدمة بمركز ذوب الاحتياجات الخاصة بكلية الدراسات العليا للطفولة جامعة عين شمس".

الفرض الفرعي الثالث: "تتحقق عناصر الاستجابة كأحد أبعاد جودة الخدمة المقدمة بمركز

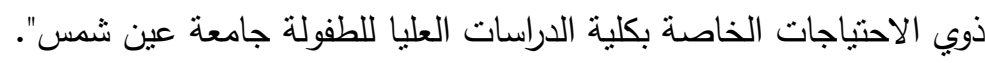




\begin{tabular}{|c|c|c|c|c|}
\hline \multicolumn{5}{|r|}{ جدول (†): نتائج الإحصاء الوصفي لعبارات الاستجابة } \\
\hline 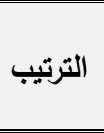 & 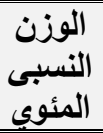 & 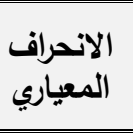 & 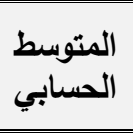 & 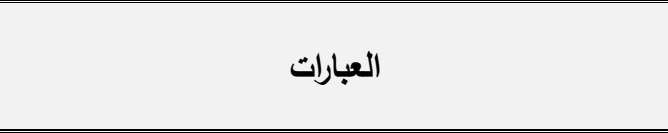 \\
\hline$r$ & $\begin{array}{c}7 \varepsilon, 7 \\
V\end{array}$ & $\cdot$ & $1,9 \leq$ & 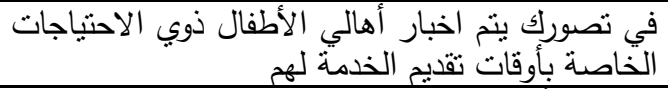 \\
\hline$r$ & 7^, & $\cdot, 01$ & $r, \cdot \varepsilon$ & 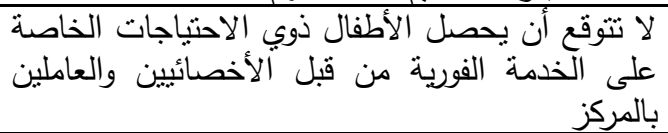 \\
\hline 1 & 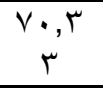 & $\cdot, \leqslant 0$ & $r, 11$ & 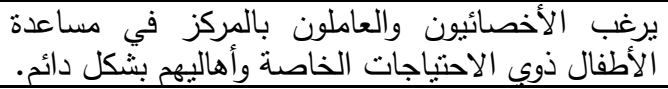 \\
\hline$\varepsilon$ & $\begin{aligned} r \\
r\end{aligned}$ & $\cdot, 71$ & 1,94 & 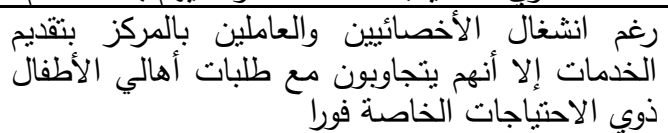 \\
\hline
\end{tabular}

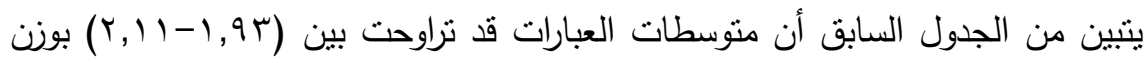

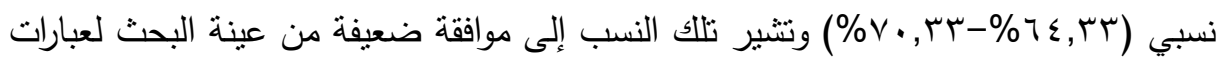

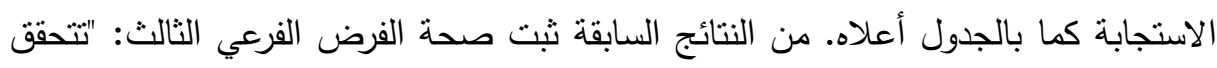

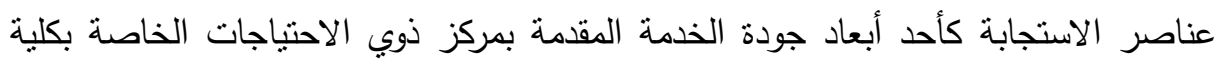
الدراسات العليا للطفولة جامعة عين شمس". الفرض الفرعي الرابع: "تتحقق عناصر الثقة كأحد أبعاد جودة الخدمة المقدمة بمركز ذوي

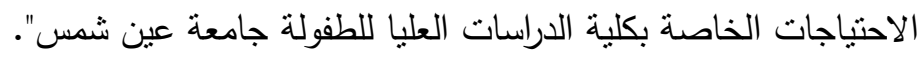


مجلة العلوم البيئية

معهد الدراسات والبحوث البيئية - جامعة عين شمس لئس

جدول (V): نتائج الإحصاء الوصفي لعبارات التقة

\begin{tabular}{|c|c|c|c|c|}
\hline الترتيب & الوزن النسبي & الالمراف & الحسابي & العبارات \\
\hline 1 & $\vee q, \ldots$ & $\cdot, 0 \leqslant$ & $r, r V$ & 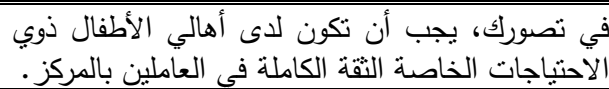 \\
\hline$r$ & $V \varepsilon, \ldots$ & $\cdot, \leqslant \wedge$ & Y,YY & 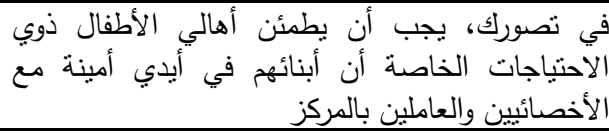 \\
\hline$\varepsilon$ & $09, \cdots$ & $\cdot, 71$ & $1, \mathrm{VV}$ & 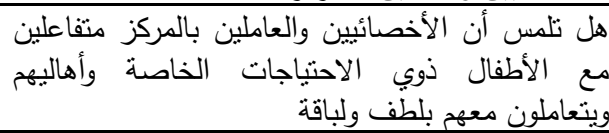 \\
\hline r & $\mathrm{V}, \mathrm{rT}$ & $\cdot, \sum \wedge$ & $r, r^{\prime}$ & 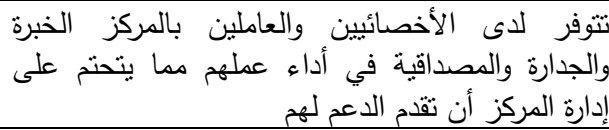 \\
\hline
\end{tabular}

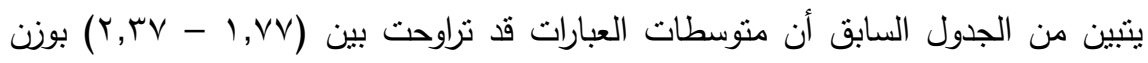

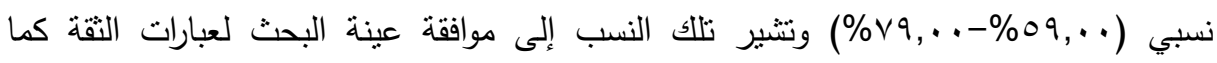
بالجدول أعلاه. من النتائج السابقة ثبت صحة الفرض الفرعي الرابع: "تتحقق عناصر التقة كأحد

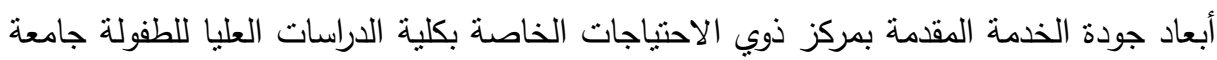

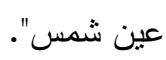
الفرض الفرعي الخامس: "تتحقق عناصر التعاطف كأحد أبعاد جودة الخدمة المقدمة بمركز ذوي

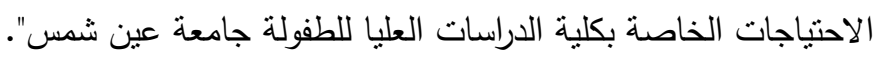

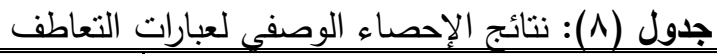

\begin{tabular}{|c|c|c|c|c|}
\hline الترتيب & الوزن النسبي & 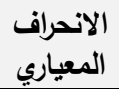 & الحتوسط & العبارات \\
\hline 1 & Mr,rr & ., or & $r, \Sigma V$ & الاحتباجات على إداصارة المركز أن تولية الأطفال ذوي \\
\hline$r$ & ru, & •, & $r, 1 \leqslant$ & 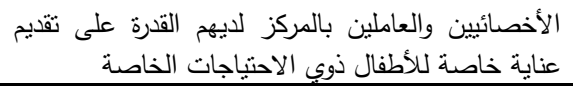 \\
\hline r & $V V, T V$ & $\cdot, \Sigma V$ & r,rr & 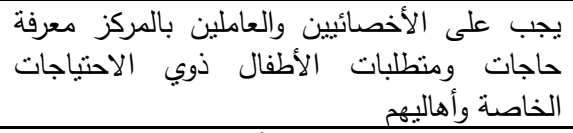 \\
\hline$\varepsilon$ & VI, V & . TV & $r, \ldots$ & ذوي الاوقتباجات إدارة المركز أهضالهـ ما لديها للأطفال \\
\hline 0 & or,.. & $\cdot, 0 \leqslant$ & 1,07 & تالطعل إدارة الاحركز بساعات الخاصة عمل حسب حاجات \\
\hline
\end{tabular}

المجلد الثامن والأربعون، الجزء الأول، ديسمبر 19. 


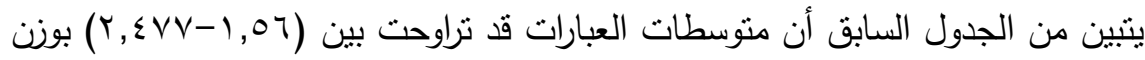

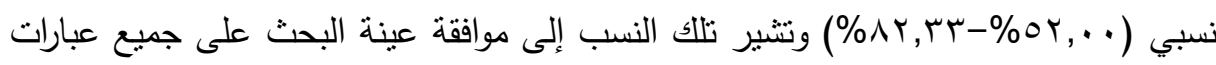
التعاطف كما بالجدول أعلاه. من النتائج السابقة ثبت صحة الفرض الفربر الفير الخامس: "تتحقق عناصر التعاطف كأحد أبعاد جودة الخدمة المقدمة بمركز ذوبي الاحتياجات الخاصة بكلية الدراسات العليا للطفولة جامعة عين شمس". ومن خلال النتائج السابقة أن أبعاد جودة الخدمة المقدمة قد تحققت بنسب منوسطة إلى لى بلى جيدة وبالتالي تعطي انطباعا عاما بأن مستوى الخدمة مقبول، ولكن الأمر ينطلب تحسين

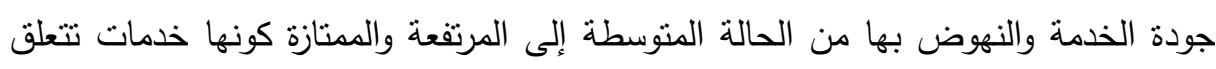

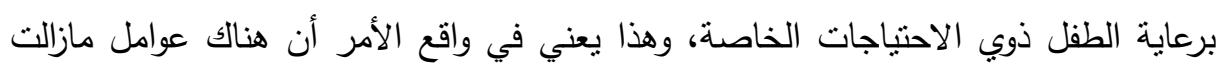

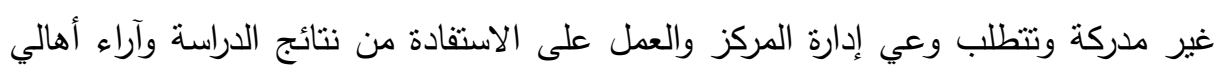
الأطفال، الأمر الذي يتطلب تحديدها ووضع الحلول المناسبة لها.

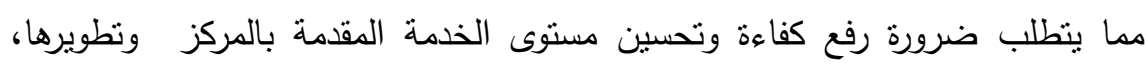

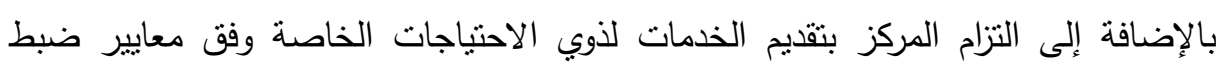

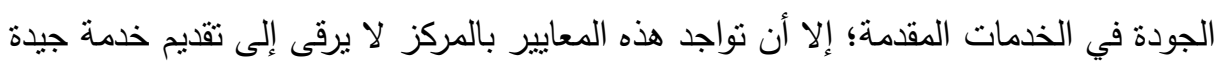

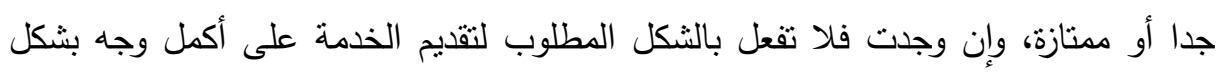

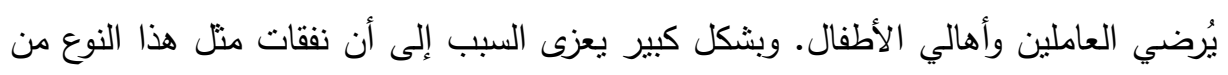

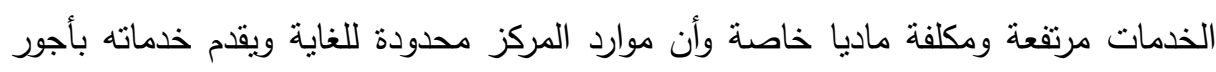
رمزية جدا للمترددين عليه، علاوة على محدودية صلاحيات العمل على اعتبار أن المركز

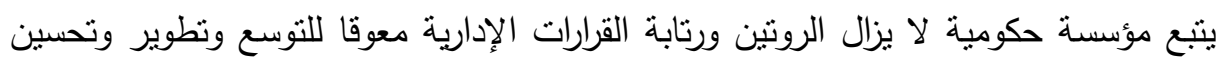
جودة الخدمة وهذا يحتاج إلى مزيد من الجهود والخبرات والامكانات والدعم المادي وتأهيل الكوادر الإدارية والفنية والأخصائيين، حيث أن تقديم منل هذه الخديد الخدمات بشكل ينافس مراكز مرموقة بدول أوروبية وخليجية يحتاج إلى فريق عمل ومتابعة دؤوبة والتزام بتطبيق معايير

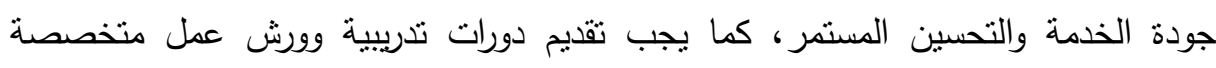

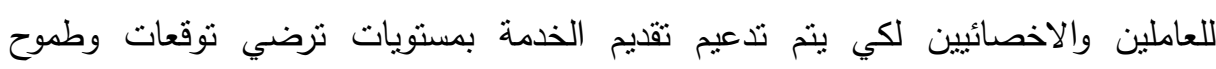

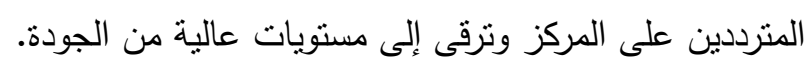


إن أبعاد جودة الخدمة وعناصرها هي مكونات رئيسية لا مناص من الالتزام بتطبيقها

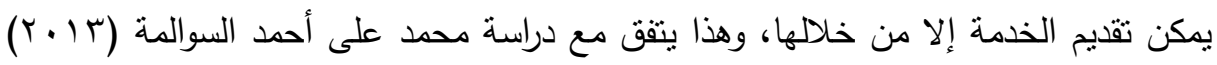

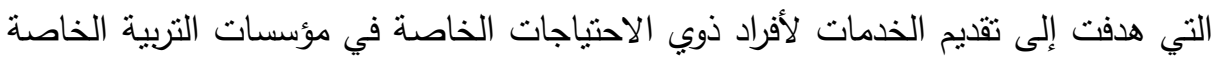
في الأردن وذلك من وجهة نظر المعلمين والمديرين وأولياء الأمور ومعرفة ما اذا كانت هنالك فروق ذات دلالة احصائية في مستوى فاعلية البرامج والخدمات المقدمة باختلاف تصنيف

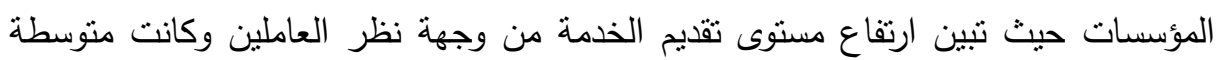

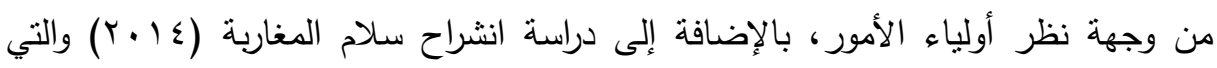

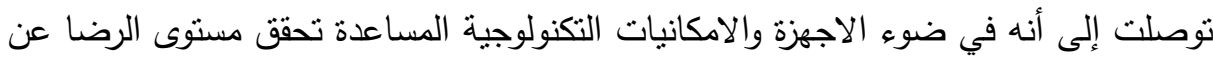

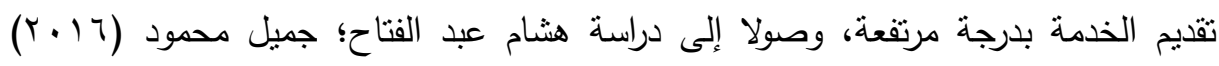

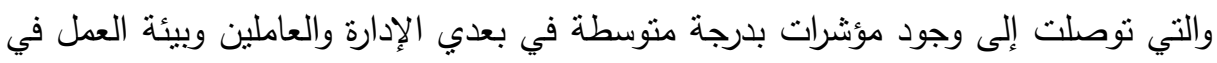
تقديم الخدمة للأطفال ذوي الاحتباجات الخاصة. ومن الجدير بالذكر هنا التتويه بأن الدرجة المتوسطة لا تعطي الانطباع بأن الوضع

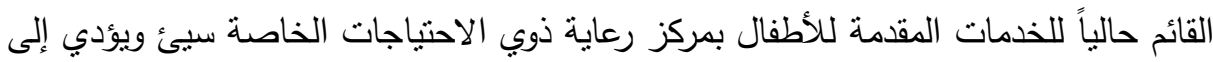

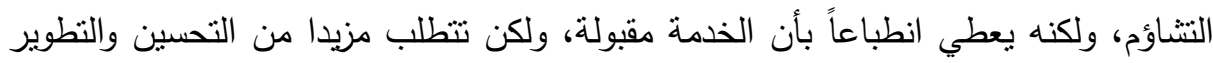

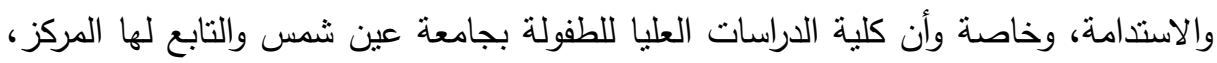
بصدد التقدم للاعتماد من الهيئة القومية لضمان الجودة والاعتماد؛ وهو ما يعني تطبيق

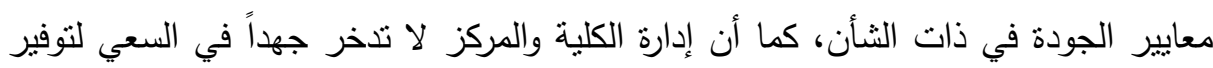

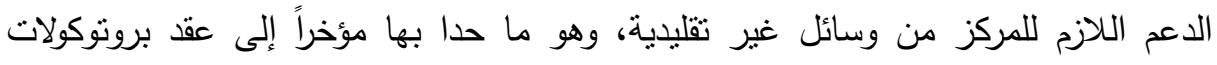
تعاون مع مؤسسات مجتمعية لضخ مزيد من الدعم بصورة المختلفة لمركز رعاية ذوي موري الاحتياجات الخاصة. 


\section{التوديجيت}

وضع خطة استراتيجية تتمل (تحسين جودة الخدمات العلاجية والتأهيلية المختلفة المقدمة بالمركز - رفع كفاءة الأخصائيين والعاملين بالمركز من خلال تقديم دورات تدريبية

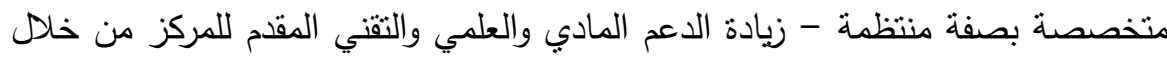
التعاون مع مؤسسات المجتمع - العمل على تحسين مستوى دخل العاملين والأخصائيين بالمركز). دعم البحوث المستقلية المتعلقة بتحسين جودة الخدمات المقدمة للأطفال ذوي الاحتياجات

\section{المرامئ2}

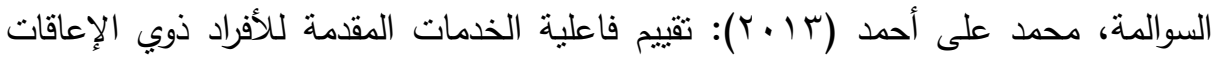

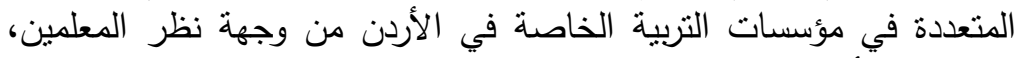

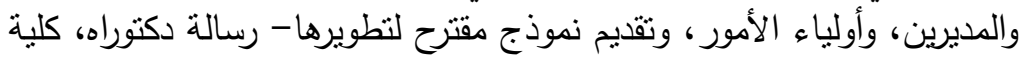
الدراسات العليا جامعة عمان، الأردن الأمرن

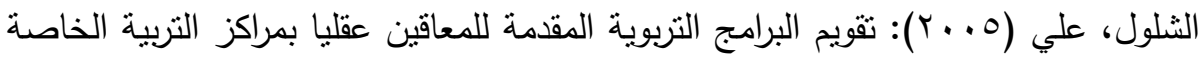

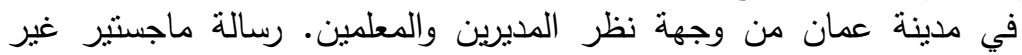
منشورة، جامعة عمان العربية للاراسات العليا: عمان، الأردن

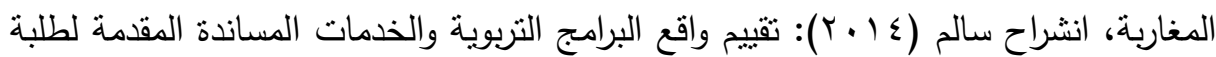

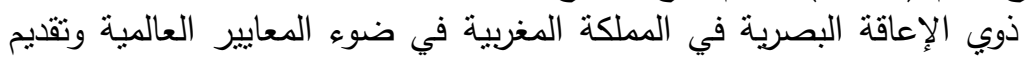

نموذج مقترح لتطويرها، رسالة دكتوراه، كلية التربية جامعة مراكش، المغية المغرب المبرة

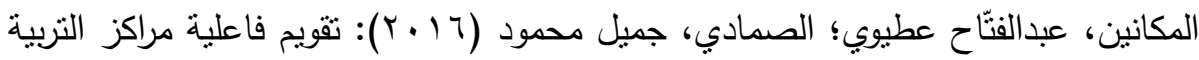
الخاصة في دولة الإمارات العربية المتحدة، مجلة جامعة الملك سعود،

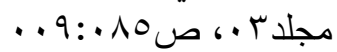

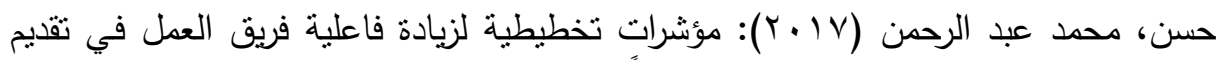

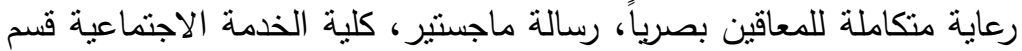
التخطيط العمراني جامعة أسيوط، جمهورية مصر العربية 


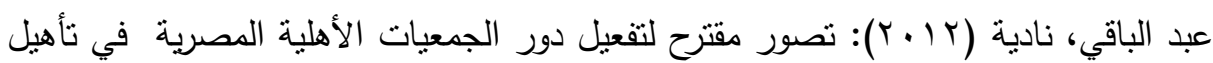

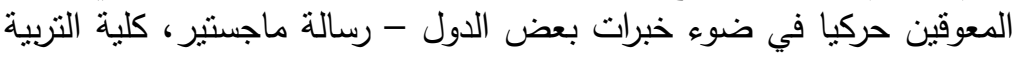
جامعة الفيوم

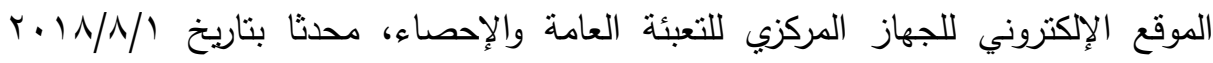
https://www.capmas.gov.eg/Pages/IndicatorsPage.aspx?pag

Bradley N.(e_id

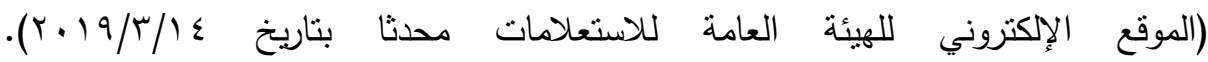
(http://www.sis.gov.eg/News/Search?lang=ar/12487r)

(Parasuraman, Zeithaml, Berry, 1988

Hedrick. Norma J. Stumbo. David L. Nordstrom: Personal Assistant Support for Students with Severe Physical Disabilities in Postsecondary Education, Journal of Postsecondary Education and Disability. 25(2). 161 - 177, 161.2011.

Nora Griffin-Shirley: A survey on the Use of Mobile Applications for People who are visually impaired, Journal of visual impairment \& blindness 111 (4): 307-323. July 2017. 


\title{
A PROPOSED FRAMEWORK FOR EVALUATING THE SERVICES PROVIDED TO CHILDREN WITH SPECIAL NEEDS - AN EMPIRICAL STUDY
}

\author{
Elsayed A. Elsheikh(1); Mohamed S. Mostafa( ${ }^{(1)}$ \\ Nader A. Fanous ${ }^{(2)}$ and Heba Allah Adem ${ }^{(2)}$
}

1) Faculty of Postgraduate, Childhood Studies, Ain Shams University

2) Faculty of Commerce, Ain Shams University

\begin{abstract}
The study aims to develop a proposed framework for evaluating the provided services to children with special needs at the Care Center of People with Special Needs, Faculty of Postgraduate Childhood Studies, Ain Shams University. The study sample consisted of (100) sample from the parents of children with special needs who deal with this Care Center. The researchers used the semi-experimental approach based on a questionnaire form to survey the effectiveness of provided services to children with special needs at the Care Center, as well as to serve the research objective. Then data were analyzed statistically by SPSS. The research results show that is a correlation between the main dimensions of services quality and the level of provided services in the care center of children with special needs in Ain-Shams University. As the level of diagnostic, treatment and rehabilitation services provided by the center plays a pivotal role in achieving the satisfaction of the families of children with special needs. The study provides a set of recommendations, such as the need to develop a strategic plan that aims to improve the quality of the various treatment and rehabilitation services at the care center through providing material, scientific and technical support, and also exchange experience through cooperation with community institutions, as well as raise the income level of staff and specialists at the care center.
\end{abstract}

